\title{
IMMUNIZATION AND MORAL HAZARD: THE HPV VACCINE AND UPTAKE OF CANCER SCREENING
}

\author{
Ali Moghtaderi \\ Avi Dor \\ Working Paper 22523 \\ http://www.nber.org/papers/w22523 \\ NATIONAL BUREAU OF ECONOMIC RESEARCH \\ 1050 Massachusetts Avenue \\ Cambridge, MA 02138 \\ August 2016
}

Scott Adams, Scott Drewianka, John Heywood, Eric Luo, and Bernard Black for their valuable comments. The views expressed herein are those of the authors and do not necessarily reflect the views of the National Bureau of Economic Research.

NBER working papers are circulated for discussion and comment purposes. They have not been peer-reviewed or been subject to the review by the NBER Board of Directors that accompanies official NBER publications.

(C) 2016 by Ali Moghtaderi and Avi Dor. All rights reserved. Short sections of text, not to exceed two paragraphs, may be quoted without explicit permission provided that full credit, including () notice, is given to the source. 
Immunization and Moral Hazard: The HPV Vaccine and Uptake of Cancer Screening Ali Moghtaderi and Avi Dor

NBER Working Paper No. 22523

August 2016

JEL No. I10,I12

\begin{abstract}
$\underline{\text { ABSTRACT }}$
Immunization can cause moral hazard by reducing the cost of risky behaviors. In this study, we examine the effect of HPV vaccination for cervical cancer on participation in the Pap test, which is a diagnostic screening test to detect potentially precancerous and cancerous process. It is strongly recommended for women between 21-65 years old even after taking the HPV vaccine. A reduction in willingness to have a Pap test as a result of HPV vaccination would signal the need for public health intervention. The HPV vaccination is recommended for women age eleven to twelve for regular vaccination or for women up to age 26 not vaccinated previously. We present evidence that probability of vaccination changes around this threshold. We identify the effect of vaccination using a fuzzy regression discontinuity design, centered on the recommended vaccination threshold age. The results show no evidence of ex ante moral hazard in the short-run. Sensitivity analyses using alternative specifications and subsamples are in general agreement. The estimates show that women who have been vaccinated are actually more likely to have a Pap test in the short-run, possibly due to increased awareness of its benefits.
\end{abstract}

\author{
Ali Moghtaderi \\ George Washington University \\ 2100 Pennsylvania Ave, Suite 300 \\ Washington, DC 20037 \\ moghtaderi@email.gwu.edu \\ Avi Dor \\ Departments of Health Policy and Economics \\ George Washington University \\ 2021 K street NW, Suite 800 \\ Washington, DC 20037 \\ and NBER \\ avidor@gwu.edu
}




\section{Introduction}

Cervical cancer is the second most common cancer related cause of death among women globally. Virtually all cervical cancers are causally related to infection by Human Papillomavirus (HPV). Approximately 70\% of cervical cancers are caused by HPV types 16 and 18 (Saslow et al., 2007). Cervical cancer is the easiest gynecological cancer to prevent, and it only requires regular screening tests and follow-ups. There are two tests for diagnosing cervical cancer, the Papanicolaou test (Pap test or Pap smear), which looks for cell change in the cervix that might ultimately become cervical cancer if it is not treated appropriately, and the HPV test, which looks for the virus (HPV) that can cause these cell changes. The Pap test is recommended for all women between ages 21 and 65 years old, while the HPV test is recommended for women older than 30 along with the Pap test (Centers for Disease Control and Prevention, 2014).

For decades the Pap test has been one of the most effective and successful cancer screenings in medicine, yet most women diagnosed with cervical cancer did not receive the test in the five years dating back to the diagnosis (Saslow et al., 2002). More recently, two HPV vaccines, Cervarix and Gardasil, became available in the market. These vaccines target HPV types that most commonly cause cervical cancer. The bivalent vaccine (Cervarix) and quadrivalent vaccine (Gardasil) can protect against HPV types 16 and 18, which worldwide are responsible for about 70\% of cervical cancer. Gardasil also protects against HPV types 6 and 11, which cause $90 \%$ of genital warts. These vaccines are highly effective in preventing the targeted HPV types (Skinner et al., 2008). Cervarix was approved in 2009 by the Food and Drug administration, and Gardasil was approved in 2006 (Centers for Disease Control and Prevention, 2015). Prior to these approval dates, no vaccine for HPV was available in the market. 
Despite the relative efficacy of the various HPV vaccines, regular Pap tests are recommended for women who have been sexually active even after HPV vaccination (American Cancer Society, 2014). Several important reasons account for that. First, vaccination does not protect against all HPV types not included in the first generation of the vaccines. About $30 \%$ of cervical cancer occurrences will not be prevented by the HPV vaccines. Second, protection against the targeted types cannot be expected to be absolute. Additionally, women who got the HPV vaccine after becoming sexually active might not get the full benefit of the vaccine if they already had been exposed to the virus. These factors, along with the fact that long term effects of the vaccine are unknown at the time being, suggest the need to use both prevention strategies, namely the vaccine $d$ the screening test as complements in order to minimize risks (Franco et al., 2006).

In the insurance literature, economists have drawn a distinction between ex-post and exante moral hazard (Ehrlich and Becker, 1972; Dave and Kaestner, 2009). Insurance can cause consumers to increase medical expenditures to inefficiently high levels due to a change in the relative price of health care (ex-post moral hazard), yet it also provides an incentive for people to under invest in self-protection or to engage in risky health behavior (ex-ante moral hazard). Another source of ex-ante moral hazard which has received less attention stems from Medical innovations that appear to change risk perceptions. For example, advances in heart disease treatments have contributed to the dramatic rise in obesity in the population (Peltzman, 2011), as has access to improved and lower-cost treatment for diabetes (Klick \& Stratmann, 2007). Similarly, less invasive cardiac procedures are less likely to induce reductions in smoking rates as compared with older and more intensive procedures (Margolis et al., 2014). HPV vaccination can also cause moral hazard in low income adolescents as they are more likely to get involved in 
risky sexual behaviors in response to taking the HPV vaccine compared to those who have not initiated the vaccine (Hill, 2014).

In this study, we look at the behavioral response to the HPV vaccine. Specifically, we look into the effect of vaccination on the decision to participate in Pap tests in the short run (having a Pap test in the past 12 months). If vaccination leads to a reduction in participation in Pap tests, it could potentially increase the incidence of cervical cancer. This should be of concern to public health policy makers. The empirical evidence presented by Ferris et al. (2012) shows that women are more receptive to getting the HPV vaccine when offered the choice of longer Pap test intervals, and Pap test non-compliers are more likely to opt for the HPV vaccine when a Pap test is required less frequently. A study in Australia showed that among women 2529 years of age, screening rates for those previously vaccinated were about ten percent lower than for women who had not been vaccinated (Budd et al., 2014). Women who reported receipt of the HPV vaccine are more likely than those not vaccinated to plan to receive a Pap test within three years (Price et al., 2011). However, these findings might not be causal since women who are more health conscious are also more likely to get vaccinated and to have a Pap test administered. Moreover, intention to have a Pap test does not necessarily lead to having it done.

This paper contributes to the literature by investigating the actual behavior (rather than intention) of women having Pap tests after HPV vaccination. Moreover, it addresses an econometric issue in the estimation of the effect of vaccination on participation in Pap tests: namely that the decision to initiate the vaccine and the decision to participate in Pap tests are determined simultaneously. There might be some unobserved factors that drive both decisions thereby raising endogeneity issues, potentially leading to biased estimates. To deal with this issue, we exploit the fact that the HPV vaccination is recommended for women younger than age 
26 years old, and that the probability of vaccination should change significantly around that age. We use this cut-off point at recommended age to construct a fuzzy regression discontinuity to identify more clearly the effect of the HPV vaccine on testing.

The results indicate that vaccine initiation is positively associated with short-term probability of participation in Pap tests even after controlling for potential endogeneity. This might be the result of increased awareness that people acquire at the time of vaccination. The estimates that ignore the potential endogeneity will result in under-estimating the true effect of the vaccine initiation on the decision to participate in Pap tests.

The rest of the paper is organized as follows: the second section provides a background on recommendations for Pap test and HPV vaccination. The third section describes the data and methodology. The fourth section presents the results, while the fifth section analyses the sensitivity of the results to different specifications. Finally, the sixth section concludes.

\section{Background}

Participation in regular Pap tests has decreased the incidence and mortality rates of cervical cancer in the past 40 years causing cervical cancer to no longer be the leading cause of cancer death for women in the United States (Centers for Disease Control and Prevention, 2013). U.S. cervical cancer incidence rates and mortality rates decreased by $75 \%$ and $74 \%$ (respectively) in the 50 years following the introduction of cervical cytology in 1949 (Howe et al., 2006). The most successful strategy in cervical cancer prevention is population-based Papsmear screening programs. The introduction of screening programs in unscreened populations can result in a $60-90 \%$ reduction in cervical cancer rates within three years after implementation (Saslow et al., 2002). 
Pap tests were recommended on an annual basis, for women in the 21 to 29 age group, and once every two to three years for older women. In March 2012, the United States Preventive Services Task Force published new cervical cancer screening guidelines which increased the recommended screening intervals to once every three years in most circumstances (National Cancer Institute, 2014).

In March 2007, the Advisory Committee on Immunization Practices (ACIP) published its recommendation for the HPV vaccine (Roblin et al., 2014). The HPV vaccine is recommended for routine vaccination at the age of eleven or twelve. ACIP also recommends HPV vaccination for females up to age 26 not vaccinated previously (Centers for Disease Control and Prevention, 2010). ${ }^{1}$ Vaccination was not initially recommended for women over the age, given that the relatively older women were not included in early clinical trials for vaccines. As a result, the FDA could not approve the vaccines for the older age group (American Cancer Society, 2014). Although subsequent studies claimed that Gardasil could help protect women between the ages of 27 and 45 against infection and disease from certain HPV types (Skinner et al., 2008). After reviewing the data, the FDA concluded that the vaccine did not offer sufficient protective benefit to these women to justify a change in the recommended age. While women 27 years of age are legally allowed to get an HPV injection, they may do so only at their physician’s discretion. Since this is considered off-label use, most health insurance plans would not cover it, suggesting that both practice norms and costs act as barriers at this relatively late age. ${ }^{2}$ The vast majority of

\footnotetext{
${ }^{1}$ ACIP also recommends the quadrivalent vaccine for boys ages eleven to twelve.

${ }^{2}$ The drug company wholesale price for either vaccine is around $\$ 130$ or $\$ 140$, and a full sequence of the vaccine can cost around \$390. Adding ancillary costs, this is a considerably expensive product that can significantly affect the probability of vaccination for off-label users above the recommended age.
} 
women get vaccinated prior to age 26; however, about $13 \%$ of women were older than 26 at the time of their first injection. ${ }^{3}$

\section{Data and Methodology}

We use the National Health Interview Survey (NHIS) for this study. The NHIS is a crosssectional household interview designed to collect information for monitoring the health of the United States population. The core of the database contains four major components: Household, Family, Sample Adult, and Sample Child. The Household component collects limited demographic information on all the individuals living in a particular house. The Family component verifies and collects additional demographic information on each member from each family in the household and also collects information on health status, illness and injuries, and access to healthcare and utilization. From each family in the NHIS, one sample adult and one sample child are randomly selected and detailed health related information on each is collected. The Sample Adult component of the NHIS contains information on Pap test screening history and HPV vaccination. We use the Sample Adult database and use other components to match socioeconomic information for each individual in the sample to construct our database. We exclude the year 2008 from the analysis, since the vaccines were not approved for women older than 26 years old until middle of that year. We also exclude year 2009 in which information about vaccination and Pap tests is missing. The final sample consists of information from years 2010-2014.

To estimate the effect of HPV vaccination on the decision to participate in Pap tests, we begin by estimating:

\footnotetext{
${ }^{3}$ The National Household Interview Survey (NHIS) started collecting information about the age of respondent at the first HPV "shot" only as of 2013. 87\% of women had their first HPV shot at ages younger than 26 years old, and $13 \%$ had their first shot at ages older than 26.
} 


$$
\operatorname{stpap}_{\mathrm{ijt}}=\mathrm{f}\left(\alpha+\gamma_{\mathrm{j}}+\delta_{\mathrm{t}}+\beta_{1} \mathrm{X}_{\mathrm{ijt}}+\beta_{2} \cdot\left(\mathrm{hpv}_{\mathrm{ijt}}\right)+\varepsilon_{\mathrm{ijt}}\right)
$$

We estimate this equation using a probit model. stpap $_{\mathrm{ijt}}$ represents whether a person had a Pap test in the past 12 months (hereafter referred to as a short-run Pap test). ${ }^{4}$ The variable $h p v$ is a dummy variable which is equal to one when a respondent has initiated the sequence of HPV vaccination (dose $\geq 1$ ) in the past and otherwise zero. $\gamma_{\mathrm{j}}$ is a vector of census region dummy variable that captures time-invariant factors that cause the outcomes to be different between census regions ${ }^{5} . \delta_{t}$ is a vector of year dummies that captures the variation in outcomes in different years that are common among regions. $\mathrm{X}_{\mathrm{ijt}}$ is a vector of control covariates. It includes controls for age, race, marital status, employment status, health insurance coverage status, citizenship status, and whether a person has ever taken an HIV test. Table 1 presents the definition and coding of each variable.

It is important to point out that the decision to initiate the vaccine might be correlated with some unobserved factors that can influence the decision to participate in Pap tests simultaneously. Failing to control for the interdependence between these two decisions will lead to biased and inconsistent estimates. The direction of the bias is unclear. For example, people placing a higher value on health might seek both preventive options and treat them as complements. On the other hand, it is possible that people with limited access to regular healthcare might find the vaccination a more convenient method of protection that requires less effort and fewer follow ups.

\footnotetext{
${ }^{4}$ The NHIS reports Pap test uptake consistently only for the past 12 months. Measures of Pap uptake over longer look back periods are not collected for most years in our data. This restricts our statistical power to study the effect of HPV vaccination on uptake of Pap test in the longer time spans.

${ }^{5}$ It includes dummies for West, Midwest, Northeast, and South census regions. State of residence is not identifiable with the public use databases.
} 
A plausible strategy for identifying exogenous variation in HPV vaccine initiation is to exploit the knowledge of the rules determining the treatment. In particular, the availability of a known cut-off point in treatment assignment provides an opportunity to construct a regression discontinuity design. In principle, regression discontinuity compares the average outcome for units just left and right of the discontinuity point within a very small interval (bandwidth) around the cut-off point. Increasing the interval around the cut-off point might result in biased estimates of the treatment, specifically when the assignment variable is related to the outcome conditional on treatment assignment. A more flexible variant of the model defines the probability of treatment receipt as a function of one or more continuous assignment variables (van der Klaauw, 2008).

CDC recommends the vaccine for women younger than 26 years old (Centers for Disease Control and Prevention, 2015). Therefore, one might expect the probability of vaccination to be discontinuous at this cut-off point. We use this cut-off point to construct a fuzzy regression discontinuity (RD) around this point. In a fuzzy design, treatment assignment depends on $\mathrm{k}$ in a stochastic manner, but one in which the propensity of treatment $(\operatorname{Pr}(\mathrm{T}=1 \mid \mathrm{k}))$ is again known to have a discontinuity at $\bar{K}$ (van der Klaauw, 2008). We use the discontinuity as an instrumental variable for treatment status. This new estimate can be summarized by a bivariate probit model as follows:

$$
\begin{gathered}
\operatorname{hpv}_{\mathrm{ijt}}=1\left(\alpha+\alpha_{1} \mathrm{~K}_{\mathrm{i}}+\alpha_{2}\left(\text { covered }_{\mathrm{i}}\right)+\alpha_{3}\left(\mathrm{~K}_{\mathrm{i}}{ }^{*} \text { covered }_{\mathrm{i}}\right)+\alpha_{4}\left(\mathrm{X}_{\mathrm{ijt}}\right)+\gamma_{\mathrm{j}}+\delta_{\mathrm{t}}+\mathrm{u}_{\mathrm{ijt}}>0\right) \\
\operatorname{stpap}_{\mathrm{ijt}}=1\left(\varphi+\varphi_{1} \mathrm{~K}_{\mathrm{i}}+\varphi_{2}\left(\mathrm{~K}_{\mathrm{i}}{ }^{*} \text { covered }_{\mathrm{i}}\right)+\varphi_{3}\left(\mathrm{X}_{\mathrm{ijt}}\right)+\varphi_{4}\left(\mathrm{hpv}_{\mathrm{ijt}}\right)+\theta_{\mathrm{j}}+\tau_{\mathrm{t}}+\varepsilon_{\mathrm{ijt}}>0\right) \quad 2(\mathrm{~b}) \\
\left(\begin{array}{l}
\varepsilon \\
u
\end{array}\right) \mid Z \sim N\left(\left(\begin{array}{l}
0 \\
0
\end{array}\right),\left(\begin{array}{ll}
1 & \rho \\
\rho & 1
\end{array}\right)\right)
\end{gathered}
$$


In equations 2(a) and 2(b), $\gamma \mathrm{j}$ and $\theta_{\mathrm{j}}$ are census region dummies, and $\delta_{\mathrm{t}}$ and $\tau_{\mathrm{t}}$ are year dummies. We normalize age at the cut-off point by defining variable $K_{i}=$ age- $c_{i}$, where $c_{i}$ is the cut-off point, and age is shifted so that the discontinuity occurs at $\mathrm{K}_{\mathrm{i}}=0$ ( $\mathrm{K}_{\mathrm{i}}$ is the running variable). The validity of the RD estimates depends on whether the polynomial order of the running variable provides an adequate description of the treatment variable (Angrist \& Pischke, 2009). ${ }^{6}$ We allow the relationship between the outcomes in equations 2(a) and 2(b) and $K_{i}$ to have different slopes on either side of the discontinuity. The variable covered $_{i}$ is a dummy variable that is equal to one if $\mathrm{K}_{\mathrm{i}}<0$ (person is in the recommended age of vaccination) and zero otherwise. The remaining variables are defined as in equation 1 . The results from the fuzzy regression discontinuity design can be interpreted as a local estimator in two ways. First, because it requires limiting the sample to a subset of the population near the cut-off point, the treatment effect can only be identified for the sub-population around that point. Second, in this neighborhood, the treatment effect is only identified for the compliers, namely those would either initiate the vaccination if they are in the covered age group, or would not initiate the vaccination otherwise (Imbens \& Lemieux, 2008). As long as the order of polynomial in the running variable and data bandwidth around the cutoff point are the same for the first and second stage outcomes, estimation of $\varphi_{4}$ in equation 2(b) is identical to an instrumental variable approach. ${ }^{7}$

As previously noted, the ACIP recommendation for HPV vaccination published in March 2007 stated that the vaccine should be delivered for routine vaccination for females aged eleven

\footnotetext{
${ }^{6}$ The optimal polynomial order is determined informally by visualizing the unadjusted relationship between running variable and the vaccine initiation status. As a robustness check, we allow equations 2(a) and 2(b) to have different polynomial orders.

${ }^{7}$ In theory, 2-stage least squares (2SLS) should yield similar results as the bivariate probit; however, given its properties, the 2SLS is likely to yield biased estimates in small samples. Since we need to restrict our analysis sample to a narrow bandwidth around the cut-off point, we did not opt for this model. Moreover, non-linear models fit these data better.
} 
and twelve, and for women up to age 26 not previously vaccinated. HPV vaccine is delivered in three doses over the course of six months, and as a result, respondents who were younger than 26 in September 2007 (younger than 25.5 years of age at the time of the recommendation) fall into the recommended age group. We compare this group to those individuals who turned 27 by March 2007. ${ }^{8}$ In our main analysis, we restrict the sample to 1.5 years on either side of the cutoff points.

This approach explicitly models endogeneity through the correlation parameter $\rho$ between $\varepsilon$ and $u$, and it indicates endogeneity when it is different from zero. Note that $\mathrm{Z}$ is the vector of discontinuity and exogenous variables. We impose bivariate normal distribution on the error term following Greene (2007). We restrict the sample to an interval of 1.5 years before and after the cut-off point in order to have a small interval around the cut-off point with a sufficiently large number of observations. There is a visible discontinuity in the probability of vaccination around the cut-off point.

The variable stpap is a dummy variable which is equal to one when a person had a Pap test in the past 12 months, and zero otherwise. The variable $h p v$ is equal to one when a person had at least one dose of HPV vaccine anytime in the past, and zero otherwise. Our identification strategy is based on comparing women who were 24-25.5 years old in March 2007 (issuance date of the HPV vaccine guidelines) to women who were in the 27-28.5 age range at that point in time. We chose our study period so that the youngest women in our study are 27 (24 in March 2007) by the time of the first survey (year 2010), while the oldest are 35.5 (28.5 in March 2007) in the last survey (year 2014). Given the fact that the vast majority of women vaccinated, about

\footnotetext{
${ }^{8}$ The original recommendation by the Centers for Disease Control (CDC) implied that women one day after their $26^{\text {th }}$ birthday are excluded from the recommended age group. However, some insurance plans may provide coverage for the vaccine up to the day prior to the start of the $27^{\text {th }}$ birthday. Given the lack of clarity in this range, we excluded all women ages 26 plus 1 day to 27 from the discontinuity analysis
} 
$87 \%$ (see footnote 3 ) do so prior to age 26 , it is safe to assume that the majority of women in our sample were vaccinated more than a year before this survey, and by default, years before subsequent survey years in our data which end in 2014. Thus, the twelve-month survey lookback period for the Pap test is not an issue.

Table 2 presents the summary statistics in our final sample for women who were in the recommended age group at the time of the recommendation (March 2007), versus those who were not in the recommended age group at the time. The percent of women who had a Pap test in the past 12 months and of women who initiated and completed HPV vaccination is significantly higher among those who were in the recommended age group at the time of the recommendation. Among control covariates, there is one noteworthy item, namely that the share of women with health insurance is significantly higher among those who were not in the recommended age group at the time of the recommendation.

\section{Results}

We begin by investigating the validity of the RD design graphically. Figure 1 shows the local quadratic regressions of covariates on the running variable. No visible discontinuity is observed around the cut-off point. Figure 2 shows the discontinuity in the treatment variable at the cut-off point. There is a visible discontinuity in the probability of vaccination around the cutoff points. It indicates that people are more likely to get vaccinated if they are in the recommended age group.

Table 3 presents the results from the baseline regression (equation 1) as well as the RD design. The first column presents the marginal effects from the probit model without taking 
potential endogeneity into account. The next two columns present the marginal effects from the regression discontinuity framework along with the results from the first stage.

HPV vaccine initiation increases the probability of having a Pap test in the short run. We find a negative bias in those estimates that ignore the endogeneity. Initiating the vaccine can increase the probability of having a Pap test by 52 percentage points. This positive association might be due to an increased awareness of the existence of the test happening at the time of vaccination. Note that $\rho$ captures the potential correlation between unobservables that determines vaccine initiation and having a Pap test simultaneously -- $\rho$ is negative and statistically significant.

Although we initially have a limited number of observations in Table 3 (assumptions are relaxed in a subsequent table), the point estimates for the instrumental variable have the expected sign indicating that being in the recommended age group increases the probability of vaccine initiation significantly. We also report the F-statistics for the excluded IV from the first stage in order to provide a measure to test for weak identification. The excluded IV has an acceptable Fstatistic of around 11.

Other results in Table 3 also indicate that having any kind of health insurance can increase the probability of having a Pap test and initiating the HPV vaccination. The point estimates for income are also positive for both probit, and bivariate probit model, but only statistically significant at $10 \%$ level for the bivariate probit model. An HIV test is also positively correlated with both having a Pap test and initiating the HPV vaccine in all the specifications. If 
an individual needs to be tested for a sexually transmitted disease, it is more likely for that person to take precautionary measures for other STDs. ${ }^{9}$

Altogether, we do not find any evidence of ex-ante moral hazard; to the contrary, we find a positive association between getting vaccinated and having a Pap test in the past year. This is despite the fact that the recommendation for HPV vaccination was changed to every three years rather than annually. Note that reducing the frequency of recommended testing in the new guidelines implies that the estimated moral hazard effect is downward biased; that is, longer intervals between tests lower the probability of utilizing the routine preventive care in the later years independently of any behavioral effects. However, the guidelines can also have an opposite effect by reducing the (opportunity) cost of routine testing. ${ }^{10}$ To address this, we perform separately, analyses for the periods between 2010-2012 and 2013-2014 as well as the pooled sample. The parameter estimates of HPV were stable across the two sub-samples. In the 20132014 period, the estimated coefficient falls short of statistical significance at the conventional levels $(\mathrm{P}$-value $=0.12)$ and the F-stat from the first stage is lower. We attribute the loss of power to sample attrition ( $n=1,829$ in the $2013-14$, compared with $n=3,832$ in the pooled data) and to

\footnotetext{
${ }^{9}$ This variable is likely to be endogenous since a more health conscious person might have both HIV tests, and vaccinate against HPV. Dropping this variable from regressions will not change the results. These results are available upon request.

${ }^{10}$ To see this, we modify the expected utility framework in Ehrlich and Becker (1972) and Dave and Kaestner (2009), to include two preventive services, vaccines (v), and tests (r). Accordingly

$$
E U=(1-\pi(v, r)) * U\left(I_{1}-C_{v}-C_{r}\right)+\pi(v, r) * U\left(I_{0}-C_{v}-C_{r}\right), \text { and } \operatorname{sign} \frac{d r}{d v}=-\operatorname{sign} \frac{\partial F O C(r)}{\partial v},
$$
where $\pi$ is the probability of being sick. It can be shown that

$$
-\frac{\partial F O C(r)}{\partial v}=-\frac{\partial^{2} \pi}{\partial r \partial v} *\left(U_{1}-U_{0}\right)+\left(U_{1}^{\prime}-U_{0}^{\prime}\right) *\left(\frac{\partial \pi}{\partial r} * \frac{\partial C_{v}}{\partial v}+\frac{\partial \pi}{\partial v} * \frac{\partial C_{r}}{\partial r}\right)+\left((1-\pi) * U_{1}^{\prime \prime}+\pi * U_{0}^{\prime \prime}\right) * \frac{\partial C_{r}}{\partial r} * \frac{\partial C_{v}}{\partial v}
$$

The impact of the first term is negative given that the vaccine lowers the marginal product of routine preventative care $\left(\frac{\partial^{2} \pi}{\partial r \partial v}>0\right)$. This is the direct ex-ante moral hazard effect. However, lowering the effective price of routine preventative care (equivalent to a longer interval between routine preventative tests, $\left(\frac{\partial C_{r}}{\partial r} \downarrow\right)$ implies that the second term becomes smaller (less positive) and the last term becomes larger (less negative). Consequently, longer testing intervals may cause the vaccine effect to be lower.
} 
the fact that the proportion of women above recommended age group who got vaccinated grew over time. Given the stability of the relevant parameters over time, we opted to report results from the pooled sample only. However, the full set of results is available upon request.

Increased participation in Pap tests after HPV vaccination might be due to an increased awareness at the time of vaccination. Despite findings from clinical trials that found the vaccine to be safe and effective, perceived safety vaccine was low (Brewer \& Fazekas, 2007). There were some rumors on the internet that claimed HPV vaccination increases the risk of precancerous lesions if a person had already been exposed to HPV 16, and 18 prior to vaccination. ${ }^{11}$ As a result, a person might decide to have a Pap test after vaccination to avoid any possible adverse outcomes. Moreover, long term safety records of the vaccine were unknown at the time the recommendation was published. This might have led physicians to continue recommending Pap tests to their patient even around the time of vaccination.

It is important to point out that regression discontinuity results can be interpreted as the local average treatment effect only for the sub-population near the cut-off point. Fuzzy regression discontinuity restricts the sub-population even further to that of compliers at this value of the covariate. Generalizing the results as population average treatment effect requires strong assumptions justifying extrapolation to other sub-populations (Imbens \& Wooldridge, 2007a). We explore a variety of assumptions and their effects in the next section.

\section{Sensitivity Analysis}

We found that the age recommendation for the HPV vaccine caused a discontinuity in the probability of HPV vaccination. To verify that this association was not spurious, our first

\footnotetext{
${ }^{11}$ For example, see: http://articles.mercola.com/sites/articles/archive/2010/07/20/does-gardasil-actually-increaseyour-risk-of-cervical-cancer.aspx
} 
robustness check was to repeat the analysis using a common vaccine for which guidelines in the cervical cancer setting should not be relevant. We identified the flu vaccine as such a case; additionally, the flu vaccine is recommended annually at all ages. Thus, we did not anticipate any difference in the probability of this particular vaccine on either side of the cutoff. We ran a probit model of having a flu vaccination in the past year on the explanatory variables and discontinuity dummy. The estimated coefficient was small and highly insignificant; suggesting the observed difference in the probability of HPV vaccination is truly associated with the recommendation. ${ }^{12}$

Next, we investigate how sensitive the parametric estimates are to alternative and more flexible specifications. To implement this, we added different combinations of polynomial orders of running variables to the Pap test and the HPV vaccine initiation equations (van der Klaauw, 2008). In Table 4, we report the estimates of HPV vaccine initiation from the bivariate probit framework, as well as the coefficients of the discontinuity variable, the correlation parameter $\rho$, and the F-stat from the first stage. The results are firmly consistent with the previous findings indicating that the HPV vaccine initiation will increase the probability of the short-run Pap test.

In another set of robustness checks we alter the bandwidth around the cut-off point. A smaller interval will decrease the risk of misspecification bias, but it necessarily comes with a loss in efficiency as sample size declines. Panel A of Table 5 presents the results from using intervals shorter or longer than our base case of 1.5 years above or below the cut-off point. The estimated coefficients of HPV initiation remain positive in all the specifications, and relatively stable in magnitude. Moreover, the results are statistically significant in all cases, with the exception of the case off the narrowest bandwidth (0.5 years) where the sample size is the

\footnotetext{
${ }^{12}$ We ran a probit model flu $\mathrm{ijt}_{\mathrm{jt}}=1\left(\alpha+\alpha_{1} \mathrm{~K}_{\mathrm{i}}+\alpha_{2}\left(\operatorname{covered}_{\mathrm{i}}\right)+\alpha_{3}\left(\mathrm{~K}_{\mathrm{i}}^{*} \operatorname{covered}_{\mathrm{i}}\right)+\alpha_{4}\left(\mathrm{X}_{\mathrm{ijt}}\right)+\gamma_{\mathrm{j}}+\delta_{\mathrm{t}}+\mathrm{u}_{\mathrm{ijt}}>0\right)$, where flu is a dummy variable which is equal to one if a person had a flu shot in the past 12 months, and zero otherwise. As expected, the marginal effect of the discontinuity variable $\left(\alpha_{2}\right)$ in this model was negligible and statistically insignificant, $\left(\alpha_{2}=0.005\right.$, P value $\left.=0.845\right)$. All other coefficients were similar to the HPV model.
} 
smallest. Taken together, the results from the sensitivity analysis are consistent with our main findings; they do not provide any evidence of moral hazard.

Finally, to test the sensitivity of our results to the distributional assumptions in the bivariate probit model, we reran our analysis using a two-stage residual inclusion, that is appropriate for non-linear outcomes yet that imposes far fewer distributional assumptions. Noting that our endogenous variable is binary (HPV vaccine uptake), estimating the residuals from the first stage is more complicated than in the case of a continuous variable. We closely followed Imbens and Wooldridge (2007b) to construct generalized residuals. In the first stage, we estimated a probit model of vaccine initiation on the explanatory variables and excluded instruments (discontinuity). We then calculated generalized error based on the formula below:

$$
\text { Generalized error }=\left(\mathrm{hpv}_{\mathrm{ijt}}\right) *\left[\varphi\left(\widehat{h p}_{\mathrm{ijt}} / \Phi\left(\widehat{h p}_{\mathrm{ijt} t}\right)\right]-\left(1-\mathrm{hpv}_{\mathrm{ijt}}\right) *\left[\varphi\left(\widehat{-h p}_{\mathrm{ijt}}\right) /\left(\widehat{-h p}_{\mathrm{ijt}}\right)\right]\right.
$$

$\varphi$ is the pdf of a standard normal variable, and $\phi$ is the cdf of standard normal distribution. In the second stage, we ran a probit model for having Pap test in the past 12 months on a set of explanatory variables, hpv vaccine initiation, and generalized error estimated from the first stage. The results are reported in the first column of panel B of Table 5. We restrict the sample to 1.5 years around the cut-off point, as in our main analysis. The results are very similar to those we obtained from the bivariate probit model.

We also use the second definition of HPV vaccine uptake, namely for those who completed the entire sequence of vaccination (three or more HPV injections). Clearly, at any given time, there are fewer people who finish the full course of vaccination in comparison with those who initiated it, resulting in a smaller variation in the endogenous variable. However, it is 
conceivable that the perceived risk may be different among those who complete the full regimen of the vaccine in comparison with those who do not complete it. To explore this issue, we use the framework in equation 2, with the baseline 1.5-year bandwidth on either side of the cut-off point. These results are added to Panel B of Table 5. The estimated coefficient for vaccine completion on HPV vaccine is positive, comparable in magnitude to that found in our main analyses, and economically meaningful; however, it was not statistically significant (P-value=0.16). We attribute the lack of significance in this result to the limited variation in our endogenous regressor. ${ }^{13}$

\section{Conclusion}

We posit that vaccination can influence risk perception in people who receive a vaccine, causing them to reduce preventive efforts against related disease, thereby exhibiting ex-ante moral hazard. In this study, we specifically look at the behavioral response to HPV vaccination in terms of participation in Pap tests. Although HPV vaccination can protect against certain types of HPV and thereby reduce the incidence of cervical cancer, the protection granted by the vaccine is partial and it is not considered a perfect substitute for diagnostic screening using the Pap test.

Empirically, we exploit the established age-specific guidelines for receiving the vaccine to construct a regression discontinuity design for the Pap test decision. Because the cut-off point at the recommended age it non-deterministic (women are able to choose vaccination rather than being assigned to it), we opt for the fuzzy discontinuity design, rather than it's more commonly used "sharp" counterpart. Accordingly, we simultaneously account for both the vaccine and test

\footnotetext{
${ }^{13}$ Restricting the sample to the 1.5 year intervals around the cut-off point yielded 344 people who initiated the vaccination, but only 161 people who completed the full course.
} 
probabilities. Note that the validity of regression discontinuity results requires that on any given treatment level (vaccinated or not vaccinated), the relationship between the outcome (Pap test) and the running variable (age) be locally continuous. This assumption might be violated when there is a possibility of misreporting in the running variable; however age is unlikely to pose this problem.

Due to the sample size available to us in the 2010-2014 NHIS data for young adult females, we opted for a relatively wide bandwidth around the cut-off age for the vaccine. However, in sensitivity analyses with narrower bandwidth s, trading off smaller samples for a more clearly specified quasi-experiment, yielded similar results; our results were similarly robust to variety of specifications test. This lends greater confidence in our overall finding. Combined, our results provide no evidence of ex-ante moral hazard. Rather, we find that individuals who were in the recommended age group at the time the recommendation went into effect were more likely to receive an HPV vaccine compared to those who were not in the recommended age group (about seven percentage point), and those who had vaccinated were more likely to have a Pap test in the past twelve months (about 52 percentage points). We noted results from regression discontinuity models may not be generalized for the entire population, but they provide a valid interpretation as local average treatment effects around the cut-off point. We speculate that having the vaccine causes patients to have more interactions with health care systems around cervical cancer prevention, thereby increasing awareness of the need for continued vigilance. This may be the subject of further behavioral research. 


\section{References}

American Cancer Society. (2014). HPV Vaccines. Retrieved from: http://www.cancer.org/cancer/cancercauses/othercarcinogens/infectiousagents/hpv/huma npapillomavirusandhpvvaccinesfaq/hpv-faq-vaccine-and-pap-testing

Angrist, J.D., \& Pischke, J.-S. (2009). Mostly Harmless Econometrics: An Empiricist’s Companion. Princeton: Princeton University Press. 251-267.

Brewer, N.T., \& Fazekas, K. I. (2007). Predictors of HPV vaccine acceptability: a theoryinformed, systematic review. Preventive Medicine, 45.

Budd, A. C., Brotherton, J. ML., Gertig, D. M., Chau, T., Drennan, K., Saville, M. (2014). Cervical Screening Rates for Women Vaccinated against Human Papillomavirus. The Medical Journal of Australia, 14(1): 279-282.

Centers for Disease Control and Prevention. (2010). FDA Licensure of Quadrivalent Human Papillomavirus Vaccine (HPV4, Gardasil) for Use in Males and Guidance from the Advisory Committee on Immunization Practices (ACIP).

Centers for Disease Control and Prevention. (2013). Gynecologic Cancer, Cervical Cancer Statistics. Retrieved from http://www.cdc.gov/cancer/cervical/statistics/

Centers for Disease Control and Prevention. (2014). Gynecologic Cancer, What Should I know about Screening. Retrieved from http://www.cdc.gov/cancer/cervical/basic_info/screening.htm

Centers for Disease Control and Prevention. (2015). Human Papillomavirus (HPV), Information for Young Women-Fact Sheet. Retrieved from http://www.cdc.gov/std/hpv/stdfact-hpvvaccine-young-women.htm

Dave, D. \& Kaestner, R. (2009). Health Insurance and Ex Ante Moral Hazard: Evidence from Medicare. International Journal of Health Care Finance and Economics, 9(4): 367-390.

Ehrlich, I., \& Becker, G.S. (1972). Market Insurance, Self-Insurance, and Self-Protection. The Journal of Political Economy, 80(4): 623-648.

Farre, L., Klein, R., \& Vella, F. (2013). A Parametric Control Function Approach to Estimating the Returns to Schooling in the Absence of Exclusion Restrictions: An Application to the NLSY. Empirical Economics, 44(1): 111-133.

Ferris, D. G., Waller, J., Dickinson, A., McCracken, C., \& Goebel, A. (2012). Impact of Pap Test Compliance and Cervical Cancer Screening Intervals on Human Papillomavirus Vaccine Acceptance. Journal of Lower Genital Tract Disease, 16(1): 39-44.

Franco, E. L., Cuzick, J., Hildesheim, A., \& de, S. S. (2006). Chapter 20: Issues in Planning Cervical Cancer Screening in the Era of HPV Vaccination. Vaccine, 24: 171-7. 
Greene, W. H. (2007). Econometric analysis. Upper Saddle River, N.J: Prentice Hall, $6^{\text {th }}$ edition.

Hill, A. (2014). Medical Innovation and Moral Hazard: The Effect of HPV Vaccine on Risky Sexual Behavior. Working Paper.

Howe, H. L., Wu, X., Ries, L. A. G., Cokkinides, V., Ahmed, F., Jemal, A., Miller, B., Edwards, B. K. (2006). Annual Report to the Nation on the Status of Cancer, 1975-2003, Featuring Cancer among U.S. Hispanic/Latino Populations. Cancer, 107(8): 1711-1742.

Imbens, G.W., \& Lemieux, T. (2008). Regression discontinuity designs: A guide to practice. Journal of Econometrics, 142(2): 615-635.

Imbens, G., \& Wooldridge, J. (2007a). What's New in Economterics? Regression Discontinuity Designs. Summer Institute 2007. Cambridge, MA: National Bureau of Economic Research.

Imbens, G., \& Wooldridge J. (2007b). What's New in Economterics? Control Function and Related Models. Summer Institute 2007. Cambridge, MA: National Bureau of Economic Research.

Klein, R., \& Vella, F. (2010). Estimating a Class of Triangular Simultaneous Equations Models without Exclusion Restrictions. Journal of Econometrics, 93(2): 154.

Klick, J., \& Stratmann, T. (2007). Diabetes Treatments and Moral Hazard. The Journal of Law \& Economics, 50(3): 519.

Margolis, J., Hockenberry, J. M., Grossman, M., \& Chou, S-Y. (2014). Moral hazard and less invasive medical treatment for Coronary Artery Disease: The case of cigarette smoking. (NBER Working Paper No. 20373) Cambridge, MA: National Bureau of Economic Research.

National Cancer Institute. (2014). Pap and HPV testing. Retrieved from http://www.cancer.gov/types/cervical/pap-hpv-testing-fact-sheet

Peltzman, S. (2011). Offsetting Behavior, Medical Breakthroughs, and Breakdowns. Journal of Human Capital, 5(3): 302-341.

Roblin, D. W., Chang, A., Roblin, D. W., Ritzwoller, D. P., Carroll, N. M., Daley, M. F., \& Rees, D. I. (2014). The Influence of Deductible Health Plans on Receipt of the Human Papillomavirus Vaccine Series. Journal of Adolescent Health, 54(3): 275-281.

Saslow, D., Castle, P. E., Cox, J. T., Davey, D. D., Einstein, M. H., Ferris, D. G., Goldie, S. J., \& Garcia, F. (2007). American Cancer Society Guideline for Human Papillomavirus (HPV) Vaccine Use to Prevent Cervical Cancer and Its Precursors. CA: A Cancer Journal for Clinicians, 57(1): 7-28. 
Saslow, D., Runowicz, C. D., Solomon, D., Moscicki, A.-B., Smith, R. A., Eyre, H. J., \& Cohen, C. (2002). American Cancer Society Guideline for the Early Detection of Cervical Neoplasia and Cancer. Ca: a Cancer Journal for Clinicians, 52(6): 342-362.

Skinner, S. R., Garland, S. M., Stanley, M. A., Pitts, M., \& Quinn, M. A. (2008). Human papillomavirus vaccination for the prevention of cervical neoplasia: is it appropriate to vaccinate women older than 26? The Medical Journal of Australia, 188(4): 238-42.

Van Der Klaauw, W. (2008). Regression-Discontinuity Analysis: A Survey of Recent Developments in Economics. LABOUR, 22: 219-245. 
Table 1- Definition of control variables in the NHIS

\begin{tabular}{ll}
\hline Variable & Coding \\
\hline Race/Ethnicity & \\
$\quad$ Hispanic & $=1$ if the person is Hispanic \\
$\quad$ White & $=1$ if the person is White \\
Black & $=1$ if the person is Black \\
& $=1$ if the person is currently married \\
Marital status & $=1$ if the person holds any kind of health insurance plan \\
Insurance & $=1$ if the person worked for pay anytime in the last year \\
Employment & $=1$ if the person is American citizen \\
Citizen & $=1$ if the reported health status is greater than 3 in a 1-5 scale \\
Health status & $=1$ if person has ever been tested for HIV \\
HIV test & $=1$ if household's income is above $\$ 35,000$ \\
Income &
\end{tabular}


Table 2- Summary Statistics with Means and Standard Errors

\begin{tabular}{|c|c|c|c|}
\hline Variables & $\begin{array}{c}\text { In the recommended } \\
\text { age group }\end{array}$ & $\begin{array}{l}\text { Out of recommended } \\
\text { age group }\end{array}$ & t-test \\
\hline $\begin{array}{l}\text { Percent with Pap test in } \\
\text { the past } 12 \text { months }\end{array}$ & $\begin{array}{c}0.647 \\
(0.011)\end{array}$ & $\begin{array}{c}0.615 \\
(0.010)\end{array}$ & $2.13^{* *}$ \\
\hline $\begin{array}{l}\text { Percent initiated HPV } \\
\text { vaccination }\end{array}$ & $\begin{array}{c}0.111 \\
(0.006)\end{array}$ & $\begin{array}{c}0.030 \\
(0.003)\end{array}$ & $11.51^{* * *}$ \\
\hline $\begin{array}{l}\text { Percent completed HPV } \\
\text { vaccination }\end{array}$ & $\begin{array}{l}0.0573 \\
(0.004)\end{array}$ & $\begin{array}{c}0.010 \\
(0.002)\end{array}$ & $9.58^{* * *}$ \\
\hline Age at the time of survey & $\begin{array}{l}29.28 \\
(0.04)\end{array}$ & $\begin{array}{l}32.29 \\
(0.04)\end{array}$ & $57.27^{* * *}$ \\
\hline $\begin{array}{l}\text { Percent with health } \\
\text { insurance }\end{array}$ & $\begin{array}{c}0.758 \\
(0.008)\end{array}$ & $\begin{array}{c}0.783 \\
(0.008)\end{array}$ & $2.27^{* *}$ \\
\hline Percent Hispanic & $\begin{array}{c}0.247 \\
(0.008)\end{array}$ & $\begin{array}{c}0.238 \\
(0.008)\end{array}$ & 0.73 \\
\hline Percent black & $\begin{array}{c}0.182 \\
(0.007)\end{array}$ & $\begin{array}{c}0.195 \\
(0.007)\end{array}$ & 1.18 \\
\hline Percent White & $\begin{array}{c}0.693 \\
(0.009)\end{array}$ & $\begin{array}{c}0.698 \\
(0.009)\end{array}$ & 0.37 \\
\hline Percent married & $\begin{array}{c}0.445 \\
(0.009)\end{array}$ & $\begin{array}{c}0.480 \\
(0.009)\end{array}$ & $2.57 * *$ \\
\hline Percent employed & $\begin{array}{c}0.767 \\
(0.008)\end{array}$ & $\begin{array}{c}0.742 \\
(0.008)\end{array}$ & $2.10^{* *}$ \\
\hline Percent citizen & $\begin{array}{c}0.850 \\
(0.007)\end{array}$ & $\begin{array}{c}0.840 \\
(0.007)\end{array}$ & 0.93 \\
\hline $\begin{array}{l}\text { Percent with good health } \\
\text { status }\end{array}$ & $\begin{array}{c}0.923 \\
(0.005)\end{array}$ & $\begin{array}{c}0.911 \\
(0.005)\end{array}$ & $1.62 *$ \\
\hline Percent with HIV test & $\begin{array}{c}0.650 \\
(0.009)\end{array}$ & $\begin{array}{c}0.659 \\
(0.009)\end{array}$ & 0.66 \\
\hline $\begin{array}{l}\text { Percent with income more } \\
\text { than } 35,000 \text { per year }\end{array}$ & $\begin{array}{c}0.564 \\
(0.010)\end{array}$ & $\begin{array}{c}0.581 \\
(0.010)\end{array}$ & 1.17 \\
\hline
\end{tabular}

Average of outcome variables and control variables for women who were in the analysis sample (1.5 years around the cut-off point) for women who were in the recommended age group (24-25.5 years old in March 2007), and those who were not in the recommended age group (27-28.5 years old in March 2007) separately, and t-test for differences in mean. Sample is for the years $2010-2014$. Numbers in parentheses are standard errors. ${ }^{* * *} \mathrm{p}<0.01,{ }^{* *} \mathrm{p}<0.05,{ }^{*} \mathrm{p}<0.1$ 
Figure 1- RD Validity: Covariates

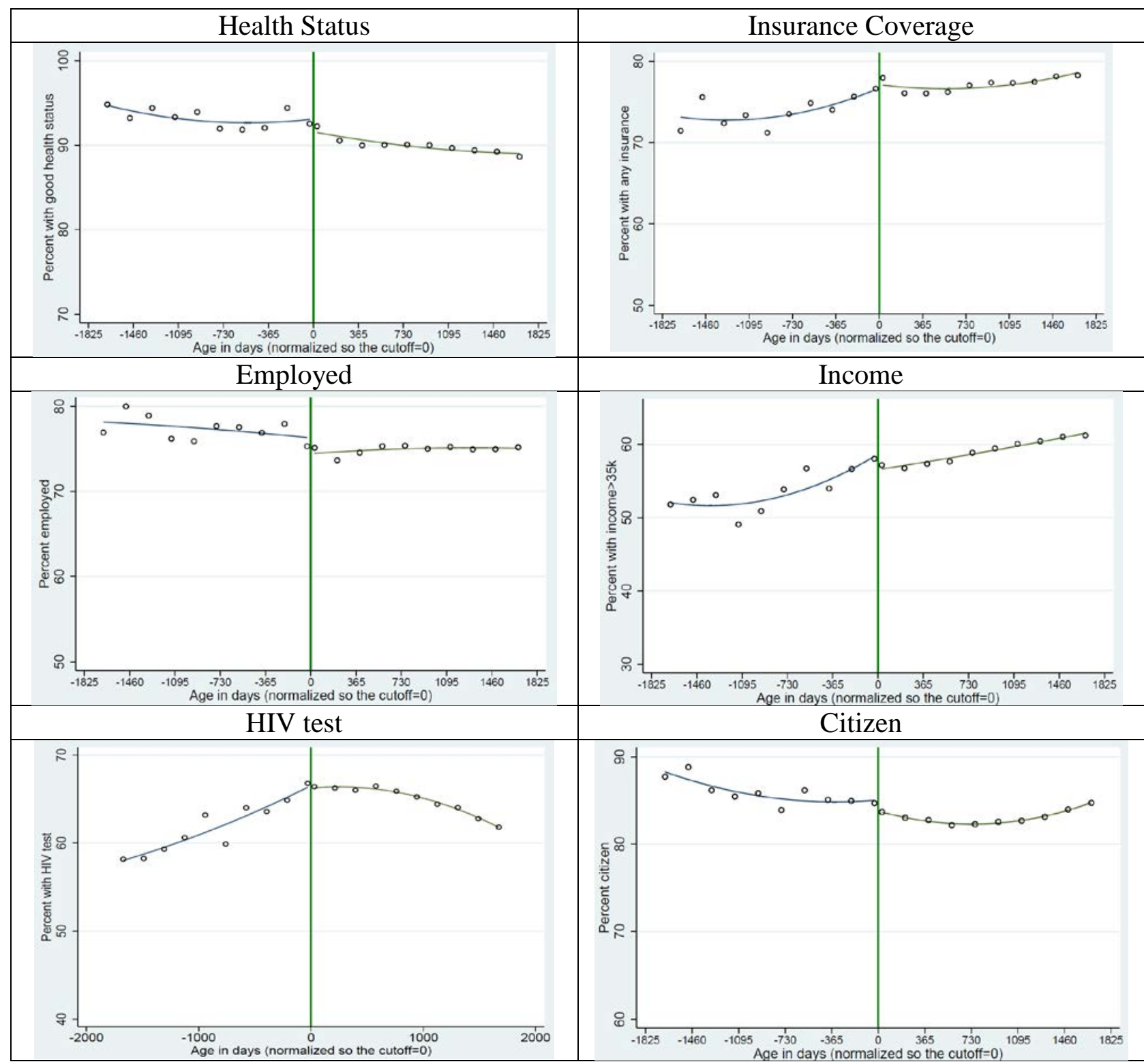

Discontinuity of covariates around the cut-off point. Points on graphs are the share of respondents with the value of 1 for that variable over a half-year bin. There are 10 bins on each side of the discontinuity. Solid lines are quadratic predictions in either side of the discontinuity. Sample is from years 2010-2014. 
Figure 2- RD Validity: Treatment Variable

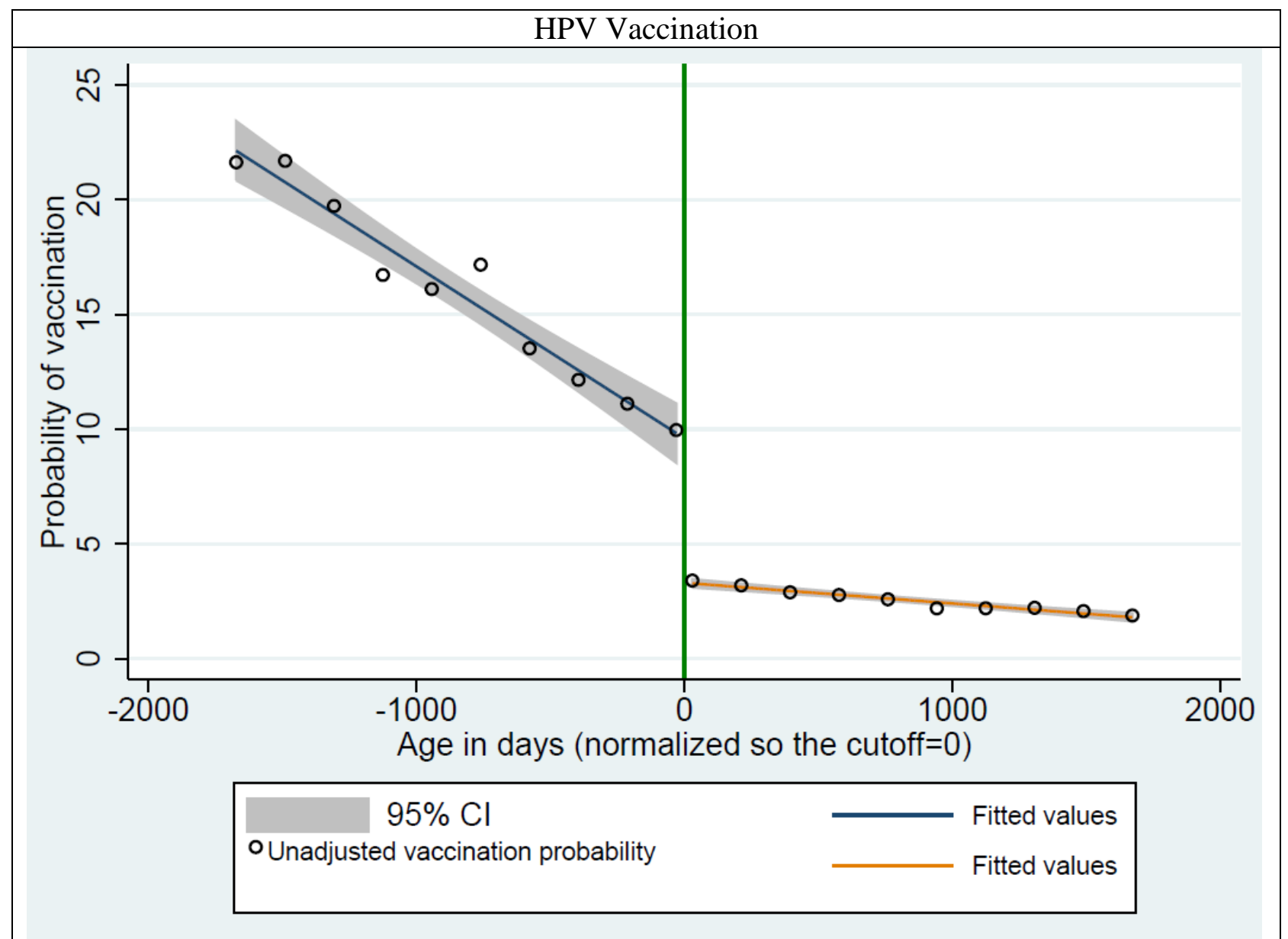

Discontinuity of treatment around the cut-off point. Points on graphs are the share of respondents with value of 1 who had initiated HPV vaccination over a half a year bin. There are 10 bins on each side of the discontinuity. Solid lines are linear predictions in either side of the discontinuity. Sample is for the years 2010-2014. 
Table 3- Effect of HPV Vaccination on Short-term Pap Test Participation

\begin{tabular}{|c|c|c|c|}
\hline & (1) & (2) & (3) \\
\hline & Probit & Bivariate Probit & Stage 1 \\
\hline VARIABLES & $\begin{array}{l}\text { Pap test in past } \\
12 \text { months }\end{array}$ & $\begin{array}{c}\text { Pap test in past } 12 \\
\text { months }\end{array}$ & $\begin{array}{l}\text { HPV vaccine } \\
\text { initiation }\end{array}$ \\
\hline \multicolumn{4}{|c|}{ Panel A- Effect of HPV vaccination on short-term Pap test using the pooled sample (2010-2014) } \\
\hline Running variable & $\begin{array}{c}-0.00013^{* *} \\
(0.00005)\end{array}$ & $\begin{array}{l}-0.00006 \\
(0.00005)\end{array}$ & $\begin{array}{l}-0.00005 \\
(0.00004)\end{array}$ \\
\hline Running variable*covered & $\begin{array}{l}0.00018^{*} \\
(0.0001)\end{array}$ & $\begin{array}{l}0.00016^{*} \\
(0.00009)\end{array}$ & $\begin{array}{c}0.00001 \\
(0.00005)\end{array}$ \\
\hline Insurance & $\begin{array}{c}0.2118^{* * * *} \\
(0.0211)\end{array}$ & $\begin{array}{c}0.1767 * * * \\
(0.0185)\end{array}$ & $\begin{array}{c}0.0082 \\
(0.0109)\end{array}$ \\
\hline Hispanic & $\begin{array}{c}0.0082 \\
(0.0224)\end{array}$ & $\begin{array}{c}0.0088 \\
(0.0203)\end{array}$ & $\begin{array}{l}-0.0135 \\
(0.0112)\end{array}$ \\
\hline Black & $\begin{array}{c}0.1465 * * * \\
(0.0280)\end{array}$ & $\begin{array}{c}0.1394 * * * \\
(0.0288)\end{array}$ & $\begin{array}{l}-0.0141 \\
(0.0162)\end{array}$ \\
\hline White & $\begin{array}{c}0.0522 * * \\
(0.0261)\end{array}$ & $\begin{array}{c}0.0470^{* *} \\
(0.0229)\end{array}$ & $\begin{array}{l}-0.0098 \\
(0.0134)\end{array}$ \\
\hline Currently married & $\begin{array}{l}-0.0011 \\
(0.0184)\end{array}$ & $\begin{array}{c}0.0129 \\
(0.0174)\end{array}$ & $\begin{array}{c}-0.0368 * * * \\
(0.0094)\end{array}$ \\
\hline Employed & $\begin{array}{c}0.0463 * * \\
(0.0200)\end{array}$ & $\begin{array}{c}0.0376^{* *} \\
(0.0176)\end{array}$ & $\begin{array}{c}0.0111 \\
(0.0104)\end{array}$ \\
\hline Citizen & $\begin{array}{c}0.0680 * * \\
(0.0277)\end{array}$ & $\begin{array}{c}0.0496^{* *} \\
(0.0243)\end{array}$ & $\begin{array}{l}0.0371^{* *} \\
(0.0157)\end{array}$ \\
\hline Health Status & $\begin{array}{c}0.0328 \\
(0.0298)\end{array}$ & $\begin{array}{c}0.0305 \\
(0.0264)\end{array}$ & $\begin{array}{l}-0.0029 \\
(0.0148)\end{array}$ \\
\hline HIV test & $\begin{array}{c}0.0985 * * * \\
(0.0172)\end{array}$ & $\begin{array}{c}0.0679 * * * \\
(0.0176)\end{array}$ & $\begin{array}{c}0.0473 * * * \\
(0.0094)\end{array}$ \\
\hline Income & $\begin{array}{l}0.0399 * * \\
(0.01940)\end{array}$ & $\begin{array}{l}0.0294 * \\
(0.0176)\end{array}$ & $\begin{array}{c}0.0124 \\
(0.0099)\end{array}$ \\
\hline HPV & $\begin{array}{c}0.1656^{* * *} \\
(0.0272)\end{array}$ & $\begin{array}{c}0.5222^{* * *} \\
(0.1162)\end{array}$ & \\
\hline Discontinuity & & & $\begin{array}{c}0.0607 * * * \\
(0.0182)\end{array}$ \\
\hline$\rho$ & & $\begin{array}{c}-.6723 * * \\
(.3121)\end{array}$ & \\
\hline F-stat & & & $11.05 * * *$ \\
\hline Observations & 3,832 & 3,832 & 3,832 \\
\hline
\end{tabular}

Note: Column 1 presents the marginal effects from probit model, column 2 presents the marginal effects from the second stage of bivariate probit model, and the third column presents the marginal effects from stage 1 from bivariate probit model. All the regressions include region and year fixed effects. Sample restricted to a 1.5 year around the cut-off point on each side. Sample is from years $2010-2014$. The numbers in parentheses are robust standard errors. ${ }^{* * *} \mathrm{p}<0.01$, ${ }^{* *}$ $\mathrm{p}<0.05,{ }^{*} \mathrm{p}<0.1$ 


\section{Table 4- Higher polynomial orders}

\begin{tabular}{|c|c|c|c|c|c|}
\hline & & & \multicolumn{3}{|c|}{$\begin{array}{l}\text { Polynomial terms of running variable in Pap } \\
\text { test equation }\end{array}$} \\
\hline & & & Linear & Quadratic & Cubic \\
\hline \multirow{4}{*}{ 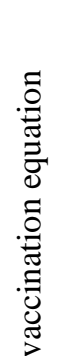 } & \multirow{4}{*}{ Linear } & HPV & $0.5222 * * *$ & $0.5420 * * *$ & $0.5480 * * *$ \\
\hline & & Discontinuity & $\begin{array}{c}0.0607 * * * \\
(0.0182)\end{array}$ & $\begin{array}{c}0.0619^{* * *} \\
(0.0177)\end{array}$ & $\begin{array}{c}0.0625 * * * \\
(0.0175)\end{array}$ \\
\hline & & $\rho$ & $\begin{array}{c}-0.6723^{* *} \\
(0.3121)\end{array}$ & $\begin{array}{c}-0.7287 * * \\
(0.3162)\end{array}$ & $\begin{array}{c}-0.7475 * * \\
(0.3146)\end{array}$ \\
\hline & & F-Stat & $11.05^{* * *}$ & $12.26 * * *$ & $12.80^{* * *}$ \\
\hline \multirow{8}{*}{ 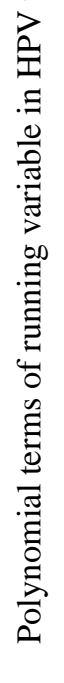 } & \multirow{4}{*}{ Quadratic } & HPV & $\begin{array}{c}0.5246 * * * \\
(0.1173)\end{array}$ & $\begin{array}{c}0.5410 * * * \\
(0.1092)\end{array}$ & $\begin{array}{c}0.5475 * * * \\
(0.1052)\end{array}$ \\
\hline & & Discontinuity & $\begin{array}{c}0.0667 * * * \\
(0.0251)\end{array}$ & $\begin{array}{c}0.0659 * * * \\
(0.0250)\end{array}$ & $\begin{array}{c}0.0673 * * * \\
(0.0249)\end{array}$ \\
\hline & & $\rho$ & $\begin{array}{c}-0.6791 * * \\
(0.3183)\end{array}$ & $\begin{array}{c}-0.7256^{* *} \\
(0.3180)\end{array}$ & $\begin{array}{c}-0.7456^{* *} \\
(0.3162)\end{array}$ \\
\hline & & F-stat & $7.07 * * *$ & $6.95^{* * *}$ & $7.29 * * *$ \\
\hline & \multirow{4}{*}{ Cubic } & $\mathrm{HPV}$ & $\begin{array}{c}0.4941 * * * \\
(0.1293)\end{array}$ & $\begin{array}{c}0.5098 * * * \\
(0.1228)\end{array}$ & $\begin{array}{c}0.5235 * * * \\
(0.1134)\end{array}$ \\
\hline & & Discontinuity & $\begin{array}{c}0.1430 * * * \\
(0.0364)\end{array}$ & $\begin{array}{c}0.1419 * * * \\
(0.0363)\end{array}$ & $\begin{array}{c}0.1406 * * * \\
(0.0361)\end{array}$ \\
\hline & & $\rho$ & $\begin{array}{l}-0.6002 * \\
(0.3152)\end{array}$ & $\begin{array}{l}-0.6396 * * \\
(0.3162)\end{array}$ & $\begin{array}{c}-0.6769 * * \\
(0.3074)\end{array}$ \\
\hline & & F-Stat & $15.52 * * *$ & $15.28 * * *$ & $15.20 * * *$ \\
\hline
\end{tabular}

Note: Different combinations of polynomial orders of running variable are included in the second and first stage of bivariate probit mode. Vertical columns show the polynomial order of running variable in stage 1 equation (HPV vaccination). Horizontal columns show polynomial order in the second stage equation (Pap test equation). All the regressions include region and year fixed effects. Sample restricted to a 1.5 year around the cut-off point on each side. Sample is from years 2010-2014. The numbers in parenthesis are robust standard errors. ${ }^{* * *} \mathrm{p}<0.01,{ }^{* *} \mathrm{p}<0.05,{ }^{*} \mathrm{p}<0.1$ 


\section{Table 5- Robustness Checks}

\begin{tabular}{|c|c|c|c|c|}
\hline \multicolumn{5}{|c|}{ Panel A- Different bandwidth around the cut-off point } \\
\hline & $(1)$ & $(2)$ & (3) & (4) \\
\hline & 0.5 year interval & 1 year interval & 2 years interval & 2.5 year interval \\
\hline \multirow[t]{2}{*}{ HPV } & 0.3116 & $0.5384 * * *$ & $0.4661 * * *$ & $0.3494 * * *$ \\
\hline & $(0.2625)$ & $(0.1119)$ & $(0.1088)$ & $(0.1129)$ \\
\hline \multirow[t]{3}{*}{ Discontinuity } & $0.0906 * * *$ & $0.0548 * *$ & $0.0753 * * *$ & $0.0738 * * *$ \\
\hline & $(0.0276)$ & $(0.0220)$ & $(0.0169)$ & $(0.0150)$ \\
\hline & -0.1990 & $-0.8191 * *$ & $-0.5558 * *$ & $-0.3630 *$ \\
\hline$\rho$ & $(0.4437)$ & $(0.3748)$ & $(0.2524)$ & $(0.2128)$ \\
\hline F-Statistics & $11.03 * * *$ & $6.16 * * *$ & $19.79 * * *$ & $24.05 * * *$ \\
\hline Observations & 1274 & 2509 & 4959 & 6232 \\
\hline \multicolumn{5}{|c|}{ Panel B- Alternative vaccine definition and two-stage residual inclusion } \\
\hline & \multicolumn{2}{|c|}{$(1)$} & \multicolumn{2}{|c|}{$(2)$} \\
\hline & \multicolumn{2}{|c|}{ Two-stage residual inclusion } & \multicolumn{2}{|c|}{$\begin{array}{c}\text { Using HPV completion instead of } \\
\text { HPV initiation }\end{array}$} \\
\hline HPV & \multicolumn{2}{|c|}{$\begin{array}{c}0.4057 * * * \\
(0.1027)\end{array}$} & \multicolumn{2}{|c|}{$\begin{array}{c}0.3558 \\
(0.2570)\end{array}$} \\
\hline Generalized error & \multicolumn{2}{|c|}{$\begin{array}{c}-0.3674 \\
(0.4173)\end{array}$} & & \\
\hline Discontinuity & \multicolumn{2}{|c|}{$\begin{array}{c}0.0607 * * * \\
(0.0145)\end{array}$} & \multicolumn{2}{|c|}{$\begin{array}{c}0.0647^{* * *} \\
(0.0150)\end{array}$} \\
\hline$\rho$ & & & \multicolumn{2}{|c|}{$\begin{array}{l}-0.3737 \\
(0.4198)\end{array}$} \\
\hline F-Statistics & \multicolumn{2}{|c|}{$19.15^{* * *}$} & \multicolumn{2}{|c|}{$19.80 * * *$} \\
\hline observations & \multicolumn{2}{|c|}{3,832} & \multicolumn{2}{|c|}{3,801} \\
\hline
\end{tabular}

Note: Panel A presents the results of bivariate probit model over different intervals around the cutoff point. Column 1 in Panel B presents the results from two-stage residual inclusion, and column 2 in Panel B presents the results using alternative definition of vaccination. Sample restricted to a 1.5 year around the cut-off point on each side in Panel B. All the regressions include region and year fixed effects. Sample is from years 2010-2014. The numbers in parenthesis are robust standard errors. ${ }^{* * *} \mathrm{p}<0.01,{ }^{* *} \mathrm{p}<0.05,{ }^{*} \mathrm{p}<0.1$ 